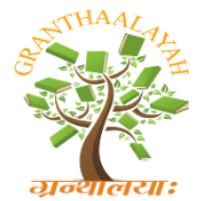

\author{
INTERNATIONAL JOURNAL OF R
GRANTHAALAYAH \\ A knowledge Repository
}

Science

\title{
EXPERIMENTAL INVESTIGATION ON MATERIAL QUALITY OF ASPHALT IN JIMMA TOWN ROAD PROJECT
}

\author{
Fisseha Wagaw Maniyazawal *1 \\ ${ }^{*}$ Civil Engineering Department, Engineering and Technology Collage, Bonga University, \\ Ethiopia
}

\begin{abstract}
The repetitive traffic loadings that the road experiences during its service life, combined with temperature fluctuations, cause rutting, fatigue and other forms of deteriorations, which ultimately degrade the performance and durability of pavement structures. According to test procedure specified by ASTM D1559 several hot asphalt mixture were prepared, the aggregate blend made by Job mix formula to obtain the percentage of mix material is give Hot-bin one is $26 \%$, Hot-bin two is $23 \%$, and Hot-bin three $51 \%$ where hot-bin one is $(20-13.2 \mathrm{~mm})$, hot-bin two $(13.2-5.0 \mathrm{~mm})$ and hot-bin three $(5.0-0.00 \mathrm{~mm})$. The result of Marshall Test on mix design for hot asphalt mixture, for wearing coarse were conclude that the material used for mix design is good, which gives Marshall stability, $12.57 \mathrm{KN}$ with optimum bitumen content of $5.2 \%$ (by weight of total aggregate). Hence the quality of aggregate is good but the influence of other factors such as poor drainage courses, level of ground water table, Varity of geological materials along the road rout and poor construction methodology caused the defect. The flow result of the Marshall mix design gives as $3.6 \%$ which is approach of upper limit of specification $4 \%$, So when flow become high in the mix it result long term deterioration of asphalt performance, hence the pavement condition along the study area has been affected by different failure types such as cracks, surface defect and disintegrating from site observation may result of this.
\end{abstract}

Keywords: Hot-Bin; Aggregates; Asphalt Layer; Hot Asphalt Mix; Optimum Bitumen Content; Marshal Mix Design.

Cite This Article: Fisseha Wagaw Maniyazawal. (2020). "EXPERIMENTAL INVESTIGATION ON MATERIAL QUALITY OF ASPHALT IN JIMMA TOWN ROAD PROJECT." International Journal of Research - Granthaalayah, 8(1), 59-68. https://doi.org/10.29121/granthaalayah.v8.i1.2020.248.

\section{Introduction}

The function of highway road pavement is to provide a safe, comfortable, convenient and economical running surface for the passage of fast-moving traffic. [8] A highway pavement is a structure consisting of superimposed layers of processed materials above the natural soil subgrade, whose primary function is to distribute the applied vehicle loads to the sub-grade. The 
pavement structure should be able to provide a surface of acceptable riding quality, adequate skid resistance, favourable light reflecting characteristics, and low noise pollution. However, there are roads built on weaker subgrade material and thus perform worse and cause losses in both serviceability and economy. The major causes of loss in the serviceability and maintenance work is rutting and surface roughness [1].

Road sector construction projects in Ethiopia are means through which development strategies are achieved. Development strategies which are fulfilled through successful road projects out end to import accessibility of urban areas, lower costs associated with transport maintenance and open more areas for development activities. Road projects, involving large amount capital, also contribute to the total economy through job creation and in a ripple effect to other business activities. The traffic volume and traffic loads on these roads are getting higher. Hence there have multi problems which are caused by poor quality subgrade or material used for construction. In large cities, the problem become one of the challenge for the economic activity of the country [7] The function of road pavement is to provide a safe, comfortable, convenient and economical running surface for the passage of fast moving traffic. [8]

A typical flexible or bituminous pavement structure consists of the following pavement courses: sub-base, base course, and bituminous wearing surface. The wearing surface may range in thickness from less than $2.5 \mathrm{~cm}$, as in the case of a surface treatment, to several centimeters of highquality paving mixture such as hot-mix asphalt concrete.[4] The wearing surface has four principal functions: to protect the base from abrasive effects of traffic, to distribute loads to the underlying layers of pavement structure, to prevent surface water from penetrating into the base and subgrade, and to provide a smooth riding surface for traffic.[2] To make asphalt with recommended strength it needs proper proportioning of the ingredients and the right selections of materials to ensure a long-lasting asphalt structure that does not require always excessive maintenance in the future. This study will conduct laboratory experiment on asphalt (wearing surface) making ingredients mainly bitumen and aggregate which helps to know the strength of normal asphalt. Pavement failure of roads in Ethiopia is becoming a common problem and great challenge, consuming a lot of money, in some cases failure is appearing even before the completion of a project in certain road projects. In most projects road surface condition defects like rutting, cracking and surface deformation are common before the design life and require a lot of maintenance cost. Under low volume road context and other higher standard roads to have better performing and long lasting nature of the road is basically depends on the material it wears; therefore studying the performance of the road surface material is key to the selection of alternative Asphalt materials with better load bearing capacity and longevity.[10] So, the purpose of this study will focus on the study of the performance of asphalt layer material used as the wearing surface of the road, taking a case study of the Jimma town road having a selected aggregate, mineral filler and bitumen material located at the road of Jimma town.

\section{Materials and Methods}

\subsection{Material}

Laboratory works conducted at Ethiopian Road Construction Corporation (ERCC) Jimma district laboratory. The Row material used in this study, the crush stone coarse aggregate and fine 
aggregate are taken from ERCC quarry which the crusher site located in Unkulu of Ana Mana Jimma Zone. The asphalt cement of 85/100 penetration grade was obtained from Ethiopian Road Construction Corporation.

\subsection{Study Area}

The study area located $354 \mathrm{kms}$ in the direction of southwest of Addis Ababa. The location of the town is $7^{0} 41^{\prime} \mathrm{N}$ Latitude and $36^{0} 50^{\prime} \mathrm{E}$ Longitude. The Town has average temperature of $20^{\circ} \mathrm{C}-30^{\circ} \mathrm{C}$ with annual rainfall $800 \mathrm{~mm}-2500 \mathrm{~mm}$ and Located in area of the altitude of $1718 \mathrm{~m}-2000 \mathrm{~m}$ above mean sea level. Climatically laid locally known as Woyn-Adaga. [5]

\subsection{Sampling Technique}

Purposive sampling methods was used as a sampling technique for the study, which is nonprobability method. Since the objective of the study was to investigate the performance of asphalt layer several material were required for producing asphalt specimen.

\subsection{Material Preparation}

The study was carefully follow the proper test procedure as described by ASTM, AASHTO and BS standards. After preparing the sample by air drying and reducing to test size using mechanical splitter in accordance to procedure outlined in AASHTO T-248 various test were conducted in ERCC.[3]

\section{Results and Discussions}

\subsection{Aggregate}

The properties of aggregates are very important to the performance of Asphalt pavements layer (APL). Synthetic aggregates, most commonly blast furnace slag from the steel industry, slate wastes and ashes, are also used in the construction of asphalt pavements [9].

\subsubsection{Aggregate Gradation of the Mix}

The hot mix asphalt is graded by percentage of different-size aggregate particles it contains. Those three types of hot-bins may combined together for gating the most well graded material for the asphalt layer material, and it is shown below in figure 3.1

The below shown figure mention as the blending result of the material for the course aggregate is out of the upper and the lower limit, this means the material need to modify using Job mix design to get the blend in the limit of upper and lower. 


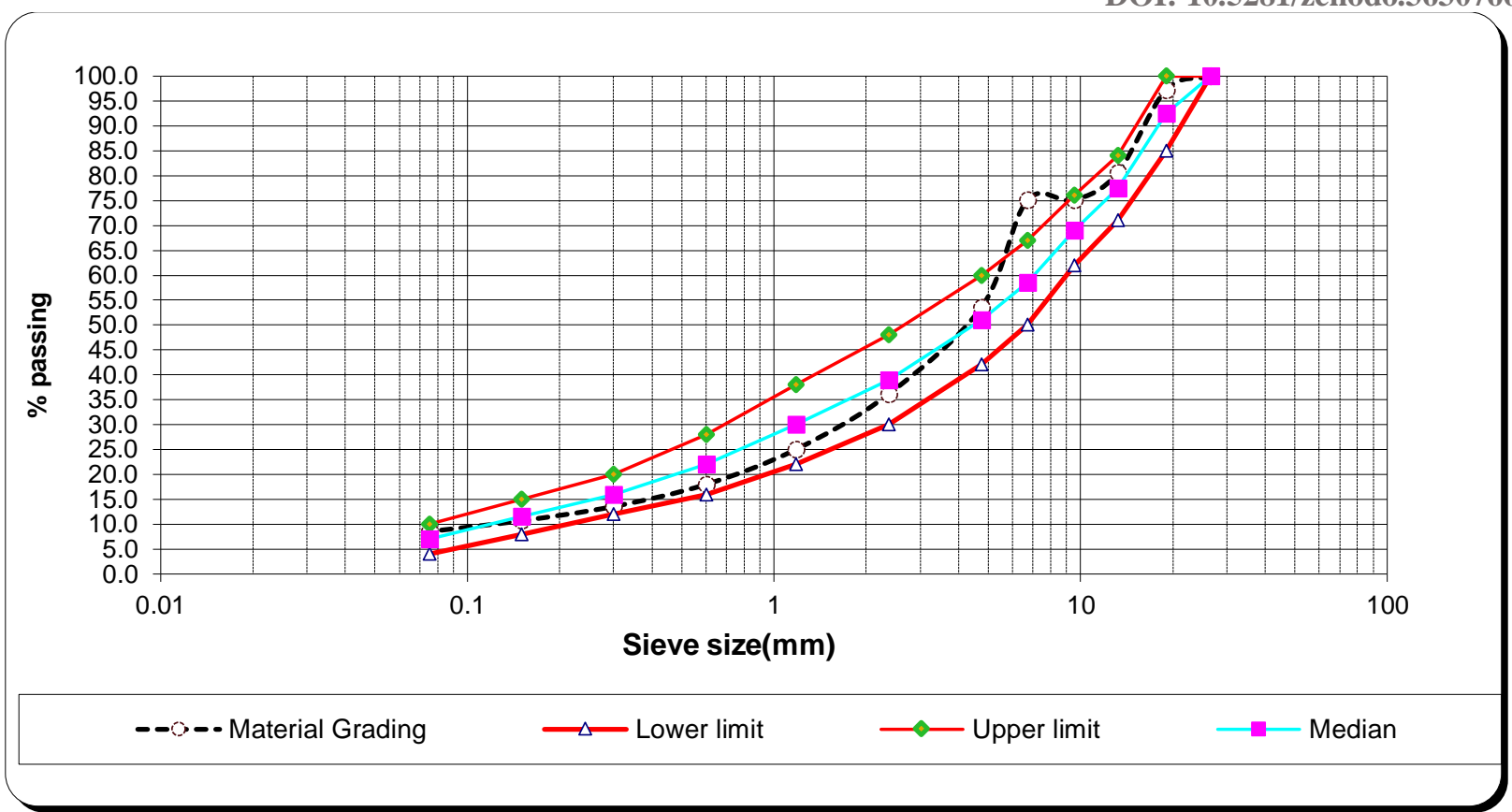

Figure 3.1: Combined Gradation of Hot-bin Aggregate

\subsubsection{Blending Aggregate}

The Job-Mix-Formula (JMF) for the aggregate particle size distribution that would be used for the preparation of mixtures shown in Fig. 3.2

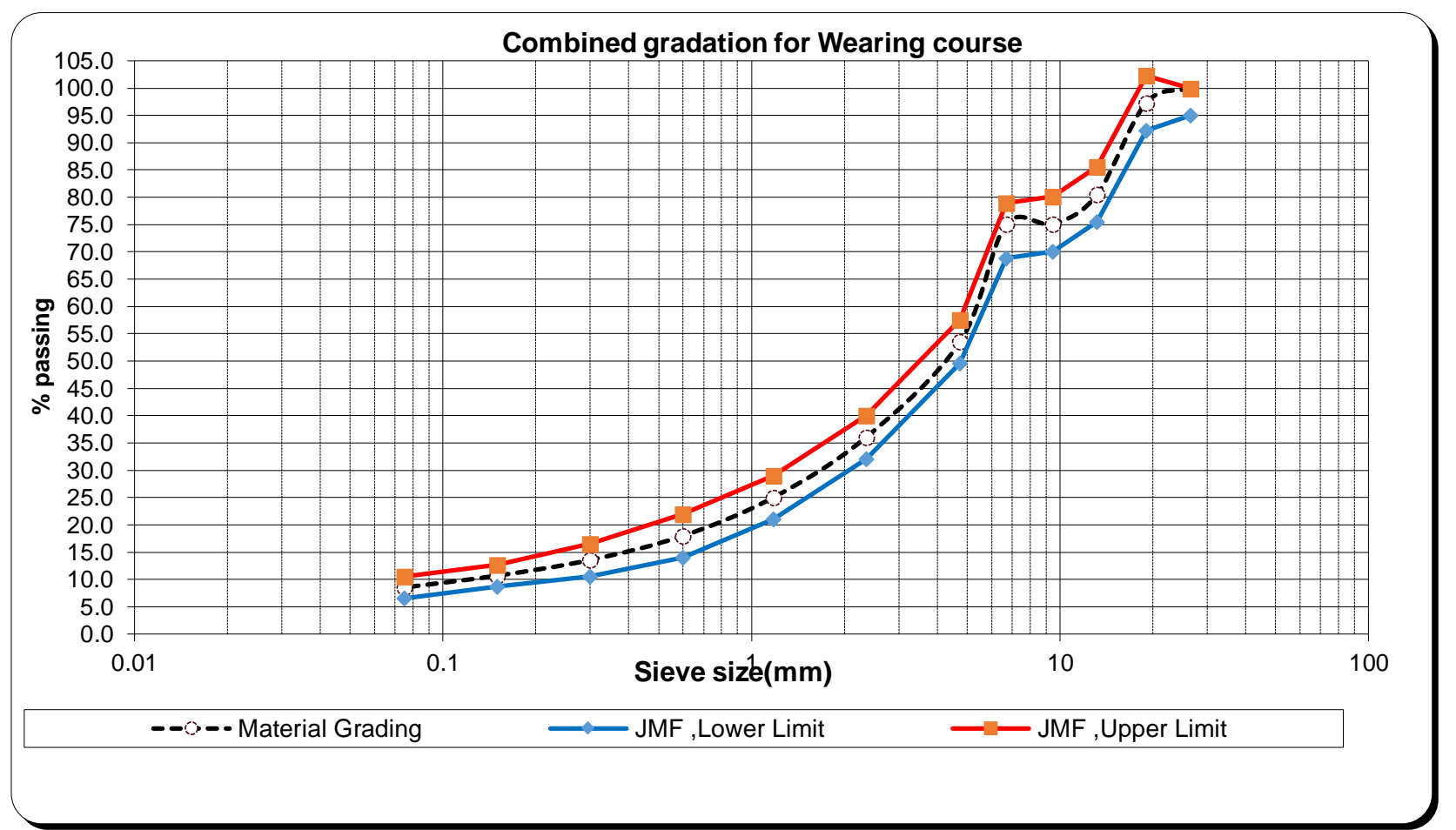

Figure 3.2: Combined Gradation of aggregate for Wearing course 
From figure above we see that the aggregate blend without filler for the Marshall Mixture preparation, which shows the blend G-1, 26\%, G-2, 23\%, and G-3, 51\%. We conclude the blend needs somehow hot-bin two 13.2/5.0 mm material to be in the specification lower and upper limit.

\subsection{Asphalt Binder Test}

The test results for binder summarized below in table 3.1 which complies with requirement of ERA manual specification.

Table 4.2: Laboratory result of Asphalt Binder

\begin{tabular}{|r|c|c|c|c|c|}
\hline No & Test Description & Unit & Test Method & Result & $\begin{array}{c}\text { Specification ERA (2002) } \\
\text { for 85/100 }\end{array}$ \\
\hline 1 & Softening Point & ${ }^{\circ} \mathrm{C}$ & AASHTO T 53 & 46 & $42-51$ \\
\hline 2 & Solubility & $\%$ & AASHTO T 44 & 99.6 & Min 99 \\
\hline 3 & Ductility & ${ }^{\circ} \mathrm{C}$ & AASHTO T 51 & $100+$ & $100+$ \\
\hline 4 & Specific gravity & $\mathrm{kg} / \mathrm{m}^{3}$ & AASHTOT 228 & 1023 & $1020 \pm$ \\
\hline 5 & Penetration & ${ }^{\circ} \mathrm{C}$ & AASHTO T49 & 90 & $85-100$ \\
\hline 6 & Loss on Heating & $\%$ & AASHTO T47 & 23 & Max 100 \\
\hline 7 & Flash Point & ${ }^{\circ} \mathrm{C}$ & AASHTO T48 & 562 & Min 232 \\
\hline
\end{tabular}

\subsection{Analysis of Physical Properties of Compacted HMA}

\subsubsection{Stability}

Anything that increases the viscosity of the asphalt cement increases the Marshall stability. The stability of HMA versus bitumen content is given in Figure 3.3.

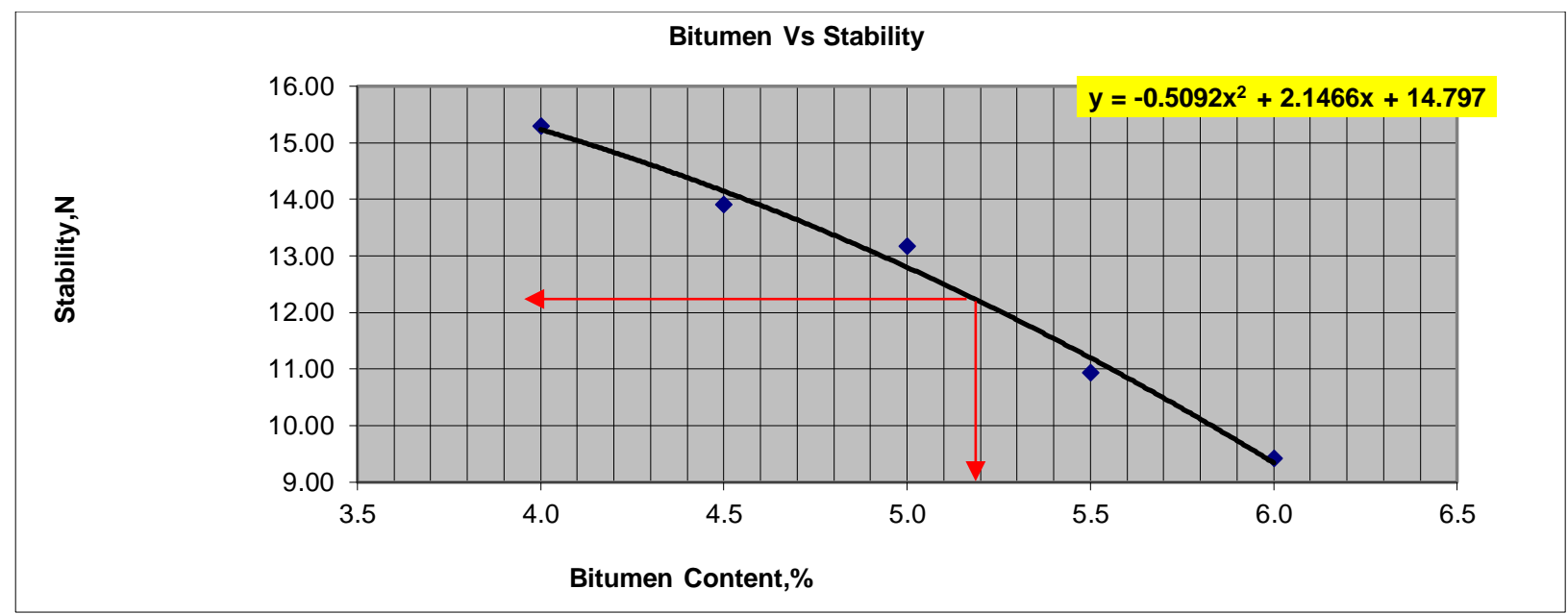

Figure 3.3: Comparison between Bitumen vs. Stability.

So, the result shows that as the bitumen content increases from 3.5 to 6.5 percent. There may be a maximum value at a bitumen content of approximately 5.2 percent this show the material blending is give good percentage of optimum content of bitumen. 


\subsubsection{Unit Weight}

The density of the compacted mix is the unit weight of the mixture (the weight of a specific volume of asphalt mixture). Density is important because proper density in the finished product is essential for lasting pavement performance. Mix properties are required to be measured in volumetric terms as well as weight is shown in Figure 3.4.

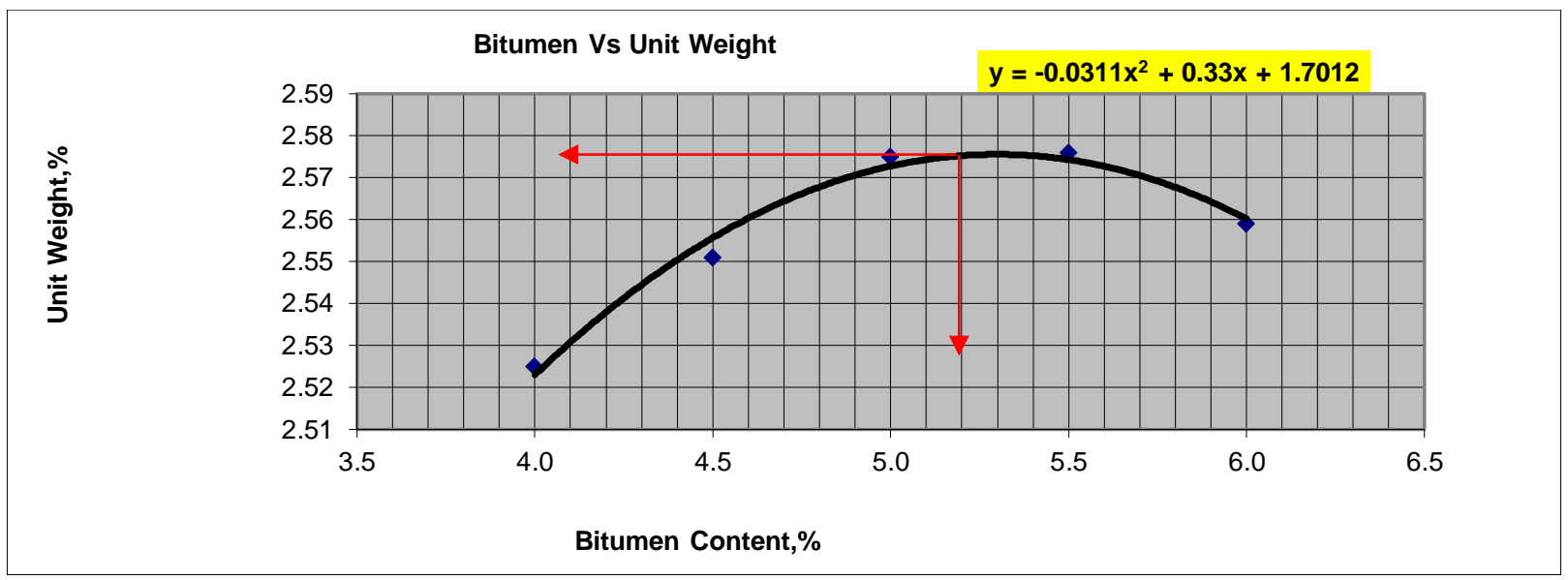

Figure 3.4: Comparison between Bitumen vs. Unit Weight

The above figure tells as the trend of unit weight verses bitumen content is usual trend which it gives the maximum unit weight given by the formula of second quadrant $\mathrm{Y}=-0.0311 \mathrm{X}^{2}+0.33 \mathrm{X}$ $+1.7012=2.75$ by using bitumen content of $5.2 \%$ which is very good when we compare with standard specification.

\subsubsection{Voids in Mineral Aggregate}

This total amount of voids significantly affects the performance of a mixture because if the VMA is too small, the mix may suffer durability problems, and if the VMA is too large, the mix may show stability problems and be uneconomical to produce. It is a common trend that, as filler content in the mixes increase, the voids in mineral aggregate decrease up to minimum value then increases at higher content.

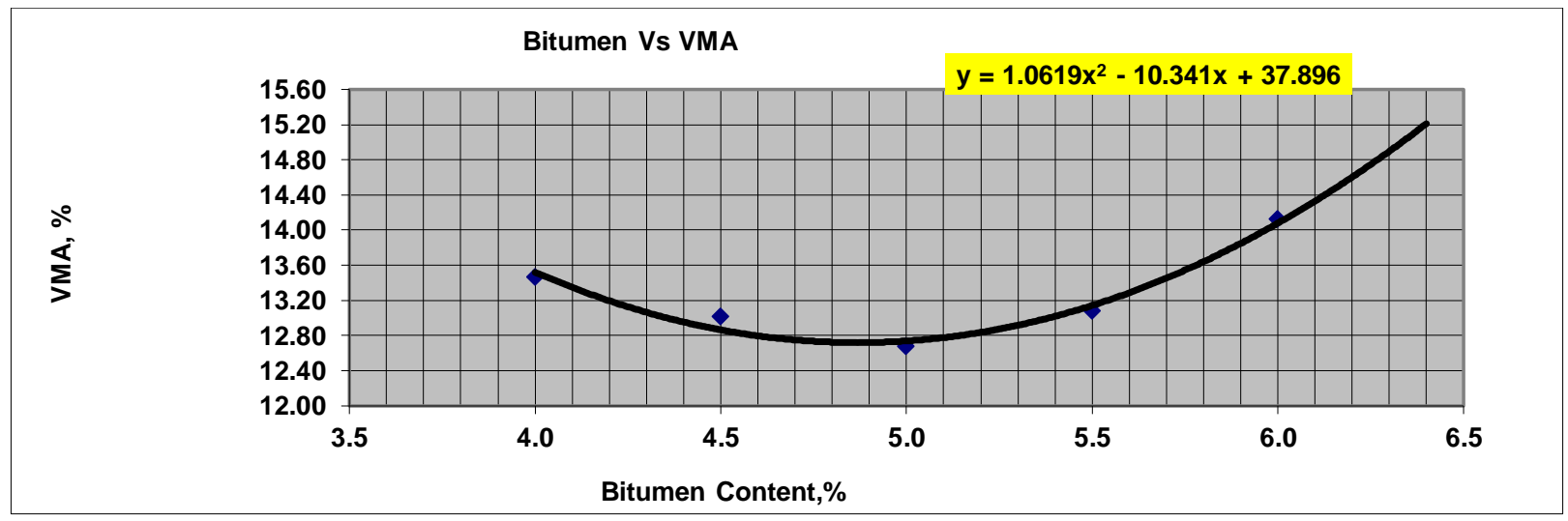

Figure 3.5: Comparison between Bitumen vs. VMA 
So, figure 3.5 tells as the result of void filled with aggregate is $14.90 \%$ which is the middle of the specification which is the upper limit is $16 \%$ and lower limit is $10 \%$.

\subsubsection{Voids Filled with Asphalt}

A void filled with asphalt (VFA) is the percentage of inter-granular void space between the aggregate particles (VMA) that contains or is filled with asphalt.

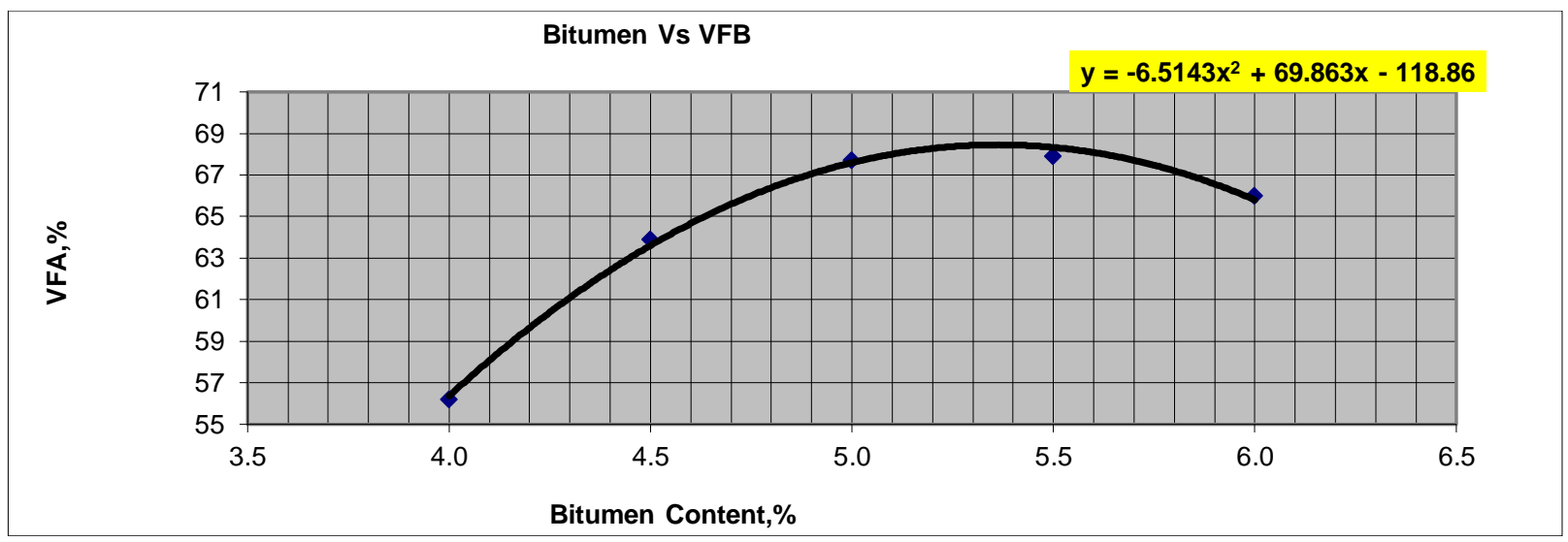

Figure 3.6: VFA, Comparison between Bitumen vs. VFA

Most specifications include percent VFA requirements range from 65 - 80 percent. Since VFA depends on both VMA and Va, the cumulative effects shown on Figure 3.6. Which gives 68.28 \% which means the middle below the average of the upper and lower limit of the specification.

\subsubsection{Air Void in the Mix}

Air voids may be increased or decreased by lowering or raising the binder content. They may also be increased or decreased by controlling the amount of material passing the No. 200 sieve in the asphalt mixture

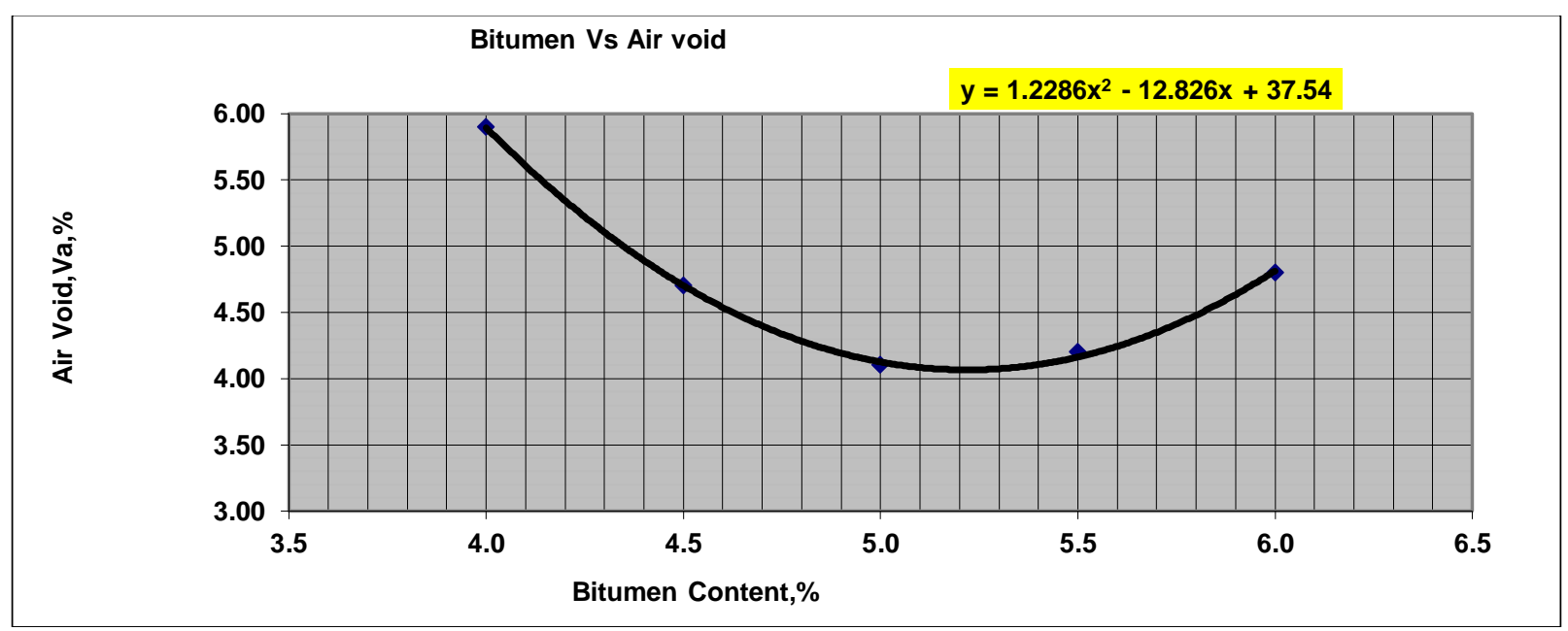

Figure 3.7: Air Void Comparison 
The more fines added to the asphalt mixture generally the lower the air voids. If a plant has a bag house dust collection system, the air voids may be controlled by the amount of fines which are returned to the asphalt mixture. Finally, the air voids may be changed by varying the aggregate gradation in the asphalt mixture. In our case the air void is $4.07 \%$ that is result of aggregate which it gives good dust material in default in the hot-bins.

\subsubsection{Flow}

Flow refers that the vertical deformation of the sample (measured from start of loading to the point at which stability begins to decrease) in $0.25 \mathrm{~mm}$.

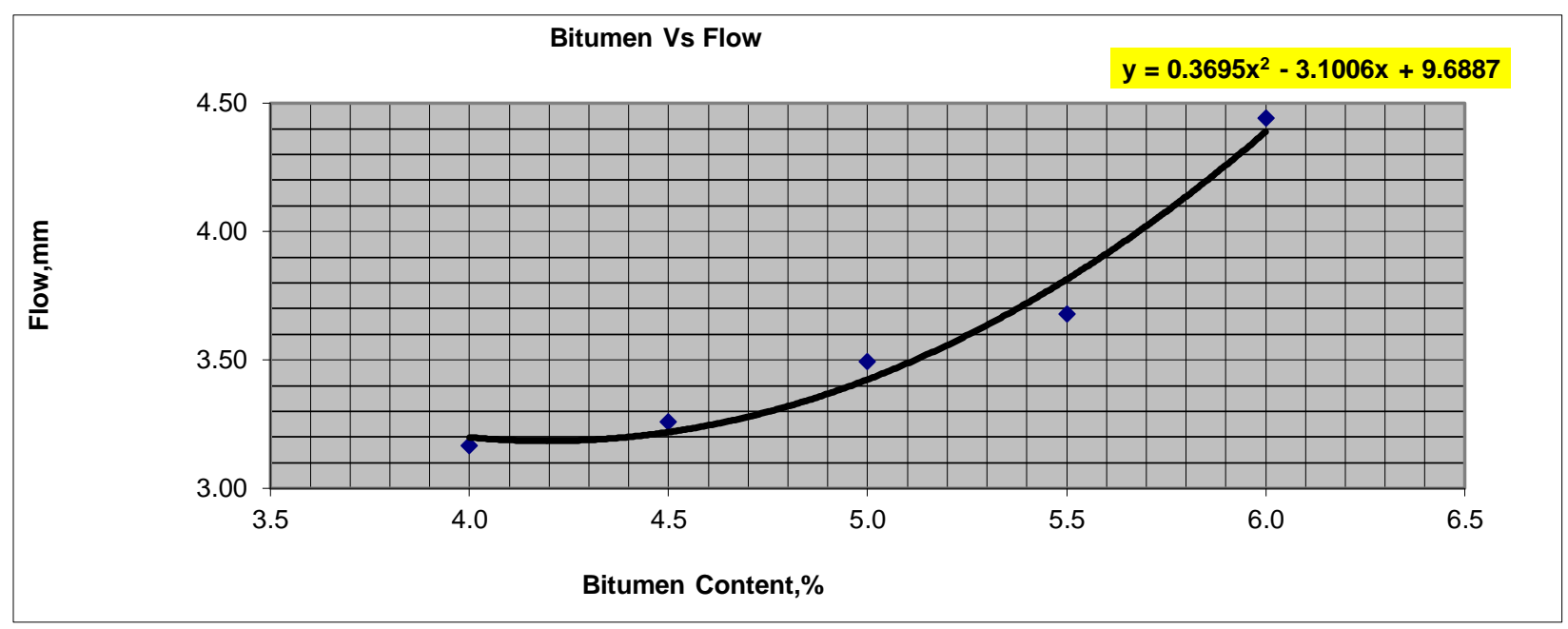

Figure 3.8: Flow Comparison between Bitumen vs flow

High flow values generally indicate a plastic mix that will experience permanent deformation under traffic, whereas low flow values may indicate a mix with higher than normal voids and insufficient asphalt for durability and one that may experience premature cracking due to mixture brittleness during the life of the pavement. Our result gives that the flow of the material in this study is good which gives $3.6 \%$ which is approach to the upper limit this means it may be affected for permanent deformation under traffic.

\subsubsection{Optimum Asphalt Content Determination}

It is considered that the effective asphalt content in the mixture determines the performance of mixtures. This can be explained as that it is the effective asphalt binder content that makes the asphalt film around the aggregate particles. If the asphalt film thickness around the aggregate particles is thick enough, various desirable characteristics such as better durability, more fatigue resistance, and higher resistance to moisture induced damage can be achieved from bituminous mixtures. But, there should be a maximum limit where up on an increase in temperature and loading, the asphalt content in the mix gets increased and results bleeding on the surface of paved road. 


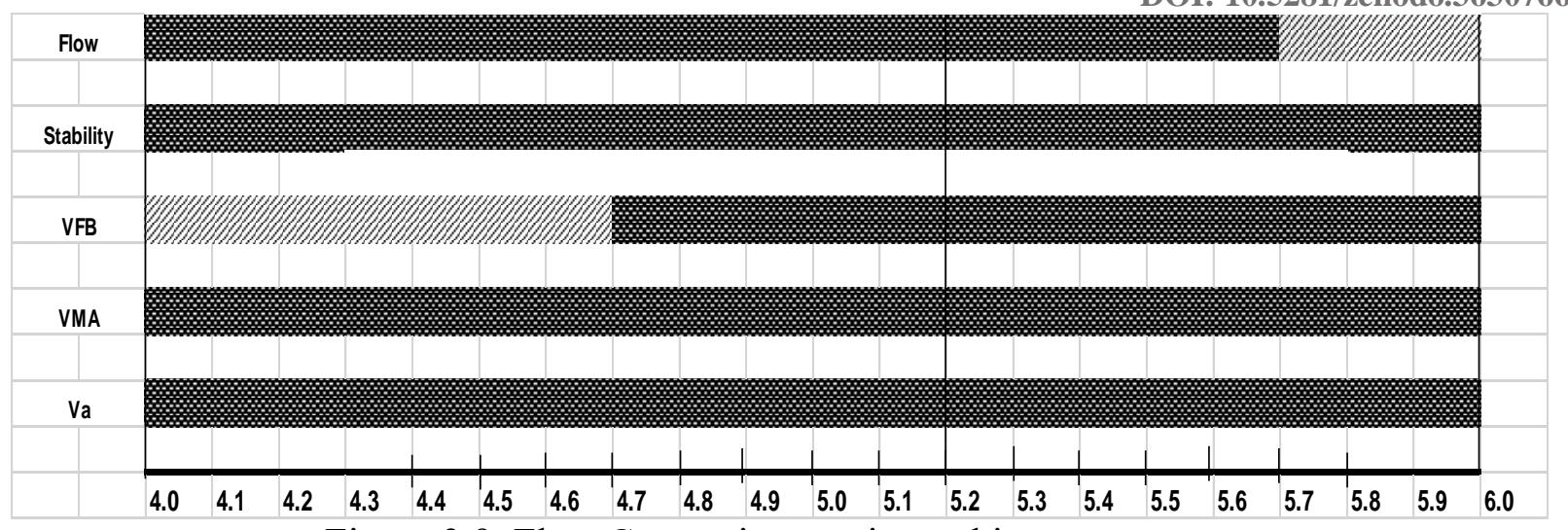

Figure 3.9: Flow Comparison optimum bitumen content

\subsection{Summary of Marshal Mix Design}

Table 4.12: Summary of Marshal Mix design of the study

\begin{tabular}{|l|l|c|c|c|}
\hline No. & \multicolumn{1}{|c|}{$\begin{array}{c}\text { Marshall Mix } \\
\text { Property }\end{array}$} & Unit & $\begin{array}{c}\text { Marshall Mix } \\
\text { result }\end{array}$ & $\begin{array}{c}\text { Specification ERA manual } \\
\mathbf{2}\end{array}$ \\
\hline 1 & OBC & $\%$ & 5.2 & 5 to 7 \\
\hline 2 & Flow & $\%$ & 3.6 & 2 to 4 \\
\hline 3 & Stability & $\mathrm{KN}$ & 12.19 & Min $9 \mathrm{KN}$ \\
\hline 4 & VFB & $\%$ & 68.28 & 60 to 85 \\
\hline 5 & Va & $\%$ & 4.07 & 3 to 6 \\
\hline 6 & VMA & $\%$ & 14.90 & 10 to 16 \\
\hline 7 & Unit weight & $\mathrm{Mg} / \mathrm{m}^{3}$ & 2.75 & - \\
\hline
\end{tabular}

\section{Conclusions and Recommendations}

Based on the laboratory test result of the experiment, the following conclusion are made:

- The Physical property of aggregate is strong material with an ACV $<25$ in percent but also has medium water absorption capacity because in most moderate but not bad, of its little bit porosity. The gradation fulfill the requirement, but lacking sufficient fines and having coarser particles but not more than upper limit of gradation in the blending of the three Hot-Bin types.

- The optimum asphalt content value were required to fulfill the Marshall requirement is $5.2 \%$ this give moderate asphalt content and it is beyond the lower and upper limit of the specification.

- The void in mineral aggregate (VFB) values obtained indicate relatively high trend that is $68.28 \%$ which is not the average of upper and lower limit this is b/c of the insufficient of fine material.

- The others property are on good median of upper and lower limit of specification which are air void and void field by bitumen.

- But the flow gives $3.6 \%$ which is so approach of the Upper limit which is $4 \%$ this may result permanent deformation under traffic to the road. So the pavement condition along the study area has been affected by different failure types such as cracks, surface defect and disintegrating. 


\section{Acknowledgements}

The authors are grateful to the editor and the reviewers for their valuable comments for improving the quality of the paper.

\section{References}

[1] Chen et al. highway materials and their property, Okulama University, thesis, 2005

[2] Department of the Army, Technical Manual (TM-5-624) Maintenance and Repair of Surface Defects, 1995

[3] ERA, Pavement Design Manual for Flexible Pavements and Gravel Roads.2002, v 2.

[4] Fiker Alebachew, Pavement Distresses on Addis Ababa City Arterial Roads, Causes and Maintenance Options, Addis Ababa University Faculty of Technology, Thesis, 2005

[5] GSE, Geology, Geochemistry, and Gravity Survey of Jima area. 2012.

[6] Hot mix asphalt, materials mixture design and construction, Asphalt overlays for highway and street rehabilitation, The Asphalt Institute, Manual series No.17 (MS-17), Second Edition, 1983

[7] Mikiyas. J G, Kabtamu G, Emer Q, Effectiveness of using Geosynthetic Material for Improvement of Road Construction and Performance, International journal, Jimma University: Institute of technology, February-2017, vol 6

[8] Oguz Acikgöz \& Rezhin Rauf, Analysis of Parameters Affecting Permanent Deformation in Road Pavement, Chalmers University of Technology, Master's thesis, 2010:64

[9] O'Flaherty C.A., Highways the Location, Design, Construction and Maintenance of Road Pavements, Fourth edition, ISBN-13: 978-0-7506-5090-8, 2007

[10] Simeneh Merga Jano, Investigation of the Performance of unsealed road sub base materials used as wearing course of gravel road, Addis Ababa Institute of Technology, Thesis, 2012.

*Corresponding author.

E-mail address: fishta.maniyazawa162@ gmail.com 